THE GEOLOGICAL HISTORY OF THE COLORADO RIVER AND PLATEAUS

II.

$\mathrm{T}$ the Pliocene period the climate of the region gradually experienced a great change. Miocene times were characterised by a moist and ordinary sub-tropical climate; the Pliocene by developing an arid one, like that which now prevails there. 'Let us look at the causes which make this climate what it is. In whatever rectilinear direction
Tre may undertake to pass from the Pliocene Country to the ocean we shall be compelled to cross some of the loftiest barriers of the Continent. It is hemmed in by range after range of high mountains. The winds laden with moisture are wrung dry long before they reach the plateaux in the heart of the province. The prevailing wind throughout the year is from the westward, and must cross the Sierra Nevada. Sweeping across the great basin it blows over many ranges, and at last strikes the Wasatch and the chain of high Plateaux which form the

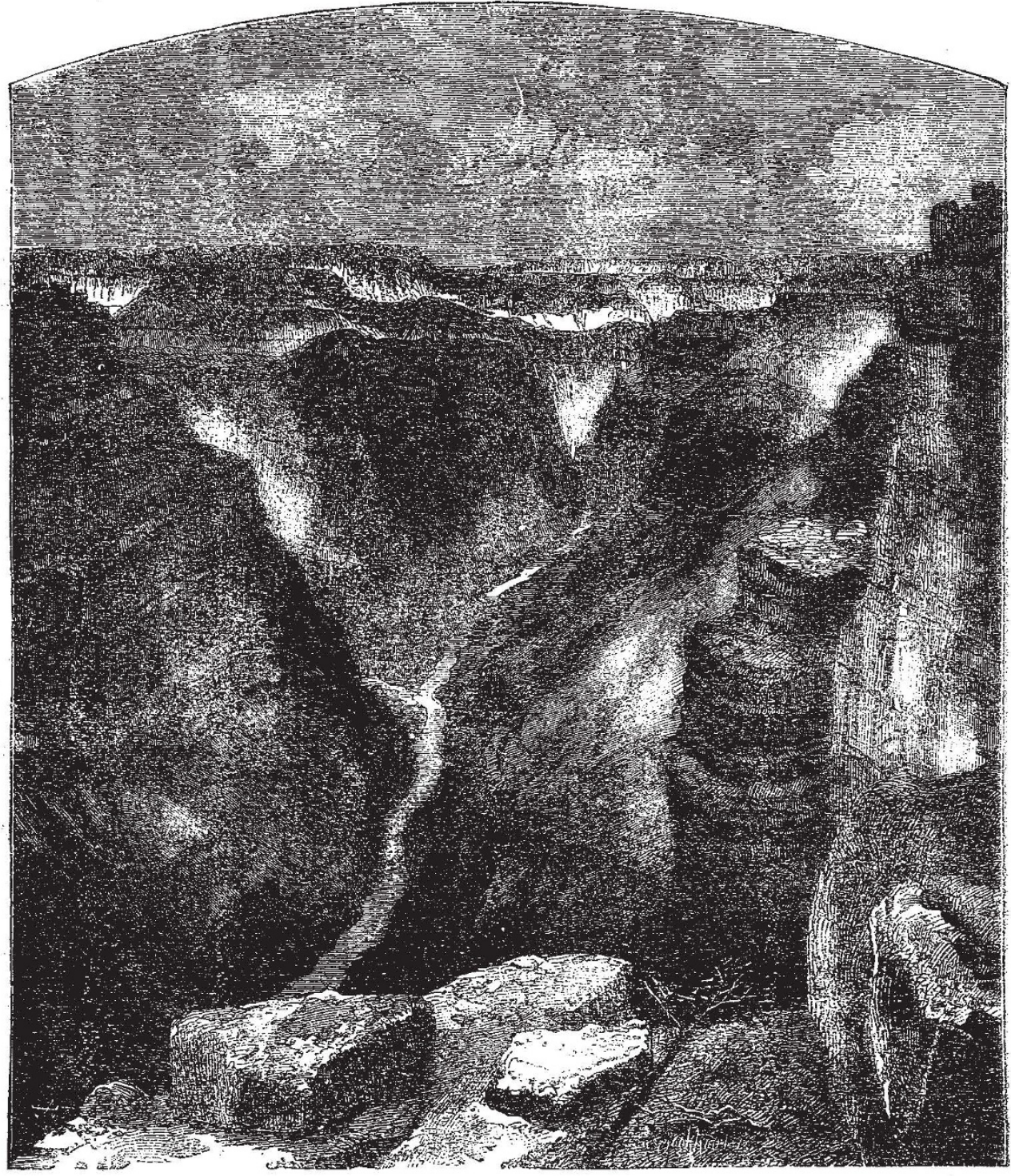

Fig. 3.-Grand Cañon, from the Middle Terrace.

western wall of the Plateaur Province. Here it is suddenly projected upward more than a mile and filings down moderately copious rains. Descending into the Cliff and Cañon Country, its humidity is so much exhausted that it can yield but the scantiest pittance of snow and showers. Thus the country is a desert. Now the strange forms impressed upon this land-its cliffs and cañons,

${ }^{x}$ By Car t. C. E. Dutton, U.S. Armo, Ass start-Geo!coist U.S. Si rv:y cf the Rocky Mountain aRegion, under Iroc. J. W. Powell, in c'arge. Conthe Rocky Mountain with their myriads of wonderful shapes and their astounding architecture-are due, as we shall presently find, in great part to the aridity. The aridity is due to the great barriers which surround it, and above all to that great barrier of high plateaux which lies upon its. western verge. Here, then, we may look for another key which may unlock another door within the vestibule. The search will not be fruitless.

The district of the bigh plateaux has been during the last four years a field of special study by myself, and has 
been investigated as thoroughly as circumstances and my very limited qualifications would admit. Its original attraction consisted in the enormous displays of volcanic energy there in former times, to which I cannot here venture to allude any further. The structure of the district is also otherwise very interesting, and has been worked out with much care and patience, and in great minuteness of detail. It will be possible at present to give nothing more than a categorical statement of certain results. To master the evidence would require the handling of a large amount of detail, and unwarrantably protract discussion.

The structure of these plateaux is identical with what Prof. Powell has described as Kaibab structure, being in fact a northward continuation of the same belt which he has described and delineated in his well-known section of the Grand Cañon which euts across this series of displacements at a right angle. The faults which have blocked out the plateaux and intervening valleys are of prodigious length, and the amounts of dislocation are very great - greater in the high plateaux than in the Kaibabs. The age of these displacements is an important landmark in the history of the country, and that age can be fixed with confidence as late Pliocene, and continuing into the Quarternary, and probably down to the present time.

With this fact in our possession as a datum we come now to the history of the cañons. The Grand Cañon first makes its appearance in the epoch of the faults. It suddenly bursts into view as a less than half-formed thing, with walls ranging from 2,000 to 2,700 feet high, late in Pliocene times. But it presents itself under somewhat unexpected circumstances, for it had been in the condition in which we first find it for a considerable period. The work of vertical erosion had long been suspended, the channels had ceased to grow deeper, and the energies of the river had for an unknowh period been employed in another kind of oeeupation to which rivers have been frequently known to betake themselves under certain common conditions. It was widening its cañon and making a flood plain in which to meander. This any river will inevitably do when it has sunk its channel to the limiting depth which local circumstances prescribe for it. When that limit is reached it will attack its own banks whether they be walls of rock or nothing but gravel and loess, and will thereafter meander or squirm from side to side. There are numerous places along the Upper Colorado and its tributaries where this is abundantly exemplified. From local causes the fall of the river has for a space been diminished, the flow has been sluggish, sediment has been deposited, the river has ceased to erode its bottom, it has attacked its walls, and the cañon nas been widened.

If now the reader will look at the section of the Grand Cañon (Fig. 3) he will perceive that it is a cañon within a cañon. The walls are in two leaps with an intermediate terrace. The upper or outer cañon is usually from three to six miles wide, and the inner cañon meanders within the upper, sometimes close to one upper wall, sometimes to the other, but usually with a middle terrace on both sides. The inner and the outer cañon represent two periods, the outer one of course being formed first-formed no doubt originally as a narrow gorge - which was widened while the river was unable to cut vertically, The middle terrace is the final flood plane of the old cañon. And now the faults ccme to our assistance in determining the two periods. The outer cañon is older than the faults; the inner one is coeval with them. The reasoning by which we determine

1 this is of the simplest order. If we were to see a fault cutting a particular stratum we should know that the stratum was older than the fault. By parity of reasoning we know that the outer cañon is older than the faut because they cut its trough and dislocate its floor faults versely. If the faults were older the river would have

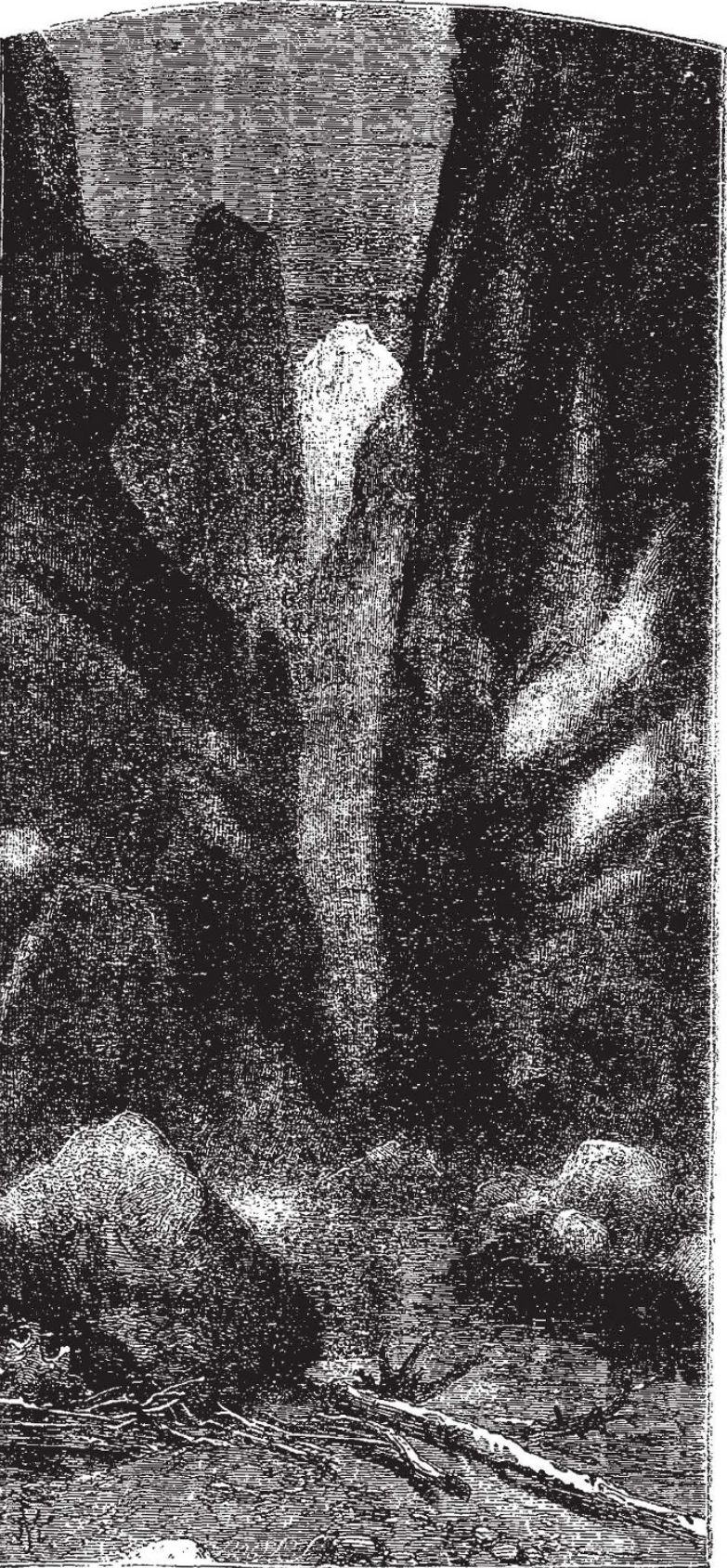

Fri. 4.--Pa-ru-nu-Weep Cañ.n, Virg:n River, a urijutary of the Colsrads.

planed an even grade acrosi them regardless of the dips of the strata just as it is doing to-day 3,000 feet below. As it is--if the side gorges would permit us to travel along the middle terrace-we should be compelled every time we crossed a fault to clamber up or down its face.

Thus, then, as we clraw near the close of the Pliocene 
period only the outer cañon was completed. When was it commenced? At present we cannot give an answer, though I hope we may soon be able to do so; but I should be surprised to find its commencement dating beyond Pliocene time. The best conjecture which I am at present able to frame would place the birth of the Grand Cañon since the middle of that epoch. The commencement of the cutting of the inner cañon was contemporary with the commencement of a new uplifting of the Kaibabs-an uplifting which extended as far north as the Wasatch, and southward to unknown regions in Arizona, through a belt having its maximum width just where the Grand Cañon crosses it. The amount of this uplifting was very variable, ranging from 2,000 to 4,000 feet. It was during this period of elevation that the faulting took place. The level of the river's bed was at once disturbed; its old energies were reawakened, and its ancient labours resumed. From that epoch to the present day the river grinding like "the mills of God" has slowly but iresistlessly sunk itself to solemn depths in the earth.

Wonderful and impressive as are the great cañons, they are no more so than some other features. Chief among the objects of special interest is the vast array of colossal cliffs, which stretch across the country with seemingly interminable length in a grouping which is half order half disorder. The number is indeed very great, their altitudes generally impressive-1,500 feet being common, and 2,000 feet not very uncommon, while the distant view of cliff rising above cliff, one beyond another, yet seeming to be united, is often seen. Each stratigraphical series has a series of cliffs, planned, sculptured, and painted in a style peculiarly its own, and the several styles differ, as decidedly and constantly as human architecture among distinct races of men. These distinguishing characters developed under one homogeneous process can be traced to the lithological composition and texture of the rocks which are powerfully contrasted between any two series. The constancy of result in any given series may also be traced to the constancy with which that series preserves one set of characters over a great extent of country. I may be mistaken-perhaps from the circumstances it is more apparent than realbut $I^{-}$imagine no region in the world hitherto explored exhibits rocks where the texture and lithological characters are so strongly pronounced, so strongly contrasted among themselves, and yet where there is so little horizontal variation in the characters of each group over vast areas.

In the Plateau Country we have to do with an arid region, and the aridity tends to reduce the amount of disintegration. On the other hand it is a lofty country giving a rapid descent to all its waterways, and their transporting power is of a very high order-the rocks are swept bare of débris and kept naked to the attacks of the elements. This tends powerfully to quicken the disintegration. The number of inches of annual rain is less than one-sixth the number in the Mississippi valley, but every inch in the plateaux may do sextuple work. Probably, however, the rate in the plateaus is on the whole slower, but the disproportion is much less than might have been anticipated if we had considered the rainfall alone.

To comprehend the origin and perpetuation of cliffs it is necessary to expand these general relations into some detail. I have stated that the attack of erosion is directed against the edges of the strata and but slightly against the horizontal surfaces. These surfaces being but little inclined, water has but little energy, as it courses over them, either to erode or to transport. But in the myriads of gulches the steepness of their sides enables the water to keep the edges of the strata naked, and the water is assisted powerfully by the aridity of the climate and the absence of vegetation. Now when the edges of a thick series of vertically heterogeneous strata are exposed, there will always be some stratum softer or more readily disin. tegrated than the others. The elements attack it, and soon a long under-cut is formed, and the rocks above robbed of a part of their support, cleave off vertically, and a great slab falls in ruins. The fallen fragments and rubble form a talus, but being now in a comminuted state, they become a much easier prey to dissolution than when in the solid wall, and they gradually moulder away. All that is necessary is that the talus should dissolve fast enough to keep the perishable stratum exposed to attack, and this is almost universally the case. The great cliffs are massive beds of sandstone and limestone, resting upon perishable calcareous and gypsiferous shales. The rapidity with which the cliff wastes away and recedes by erosion is measured by the power of resistance to weathering in the shales below and not by the massive beds on its face. By further analysing the details of erosive action, we have no difficulty in explaining the origin and causes of the different styles of architecture, the sculpture of the repetitive forms, and all their train of phenomena, both normal and abnormal.

And now a few words about the cause of cañons. This problem has been so admirably and satisfactorily solved by Messrs. Powell and Gilbert that I have no better excuse for saying anything about it than a desire to fill what would otherwise be a serious gap in the discussion.

The fall of the Colorado through the cañons is between seven and eight feet per mile-nearly twenty times as great as that of the Ohio and Mississippi and nearly seven times as great as that of the Missouri below the Yellowstone. It is a fierce torrent-a series of quicklyrecurring rapids. Its lateral gorges have usually a greaterdescent. The tools with which the river works are sand and gravel held in suspension by the water, hurled along at race-horse speed, and scouring like a sand-blast machine the naked rocks of its bed. But there is one thing more, and it is a crucial point. The Platte has about the same fall through the plains as the Colorado through the cañons; it has its sources high up in the same mountains; it flows through a desert; iit carries a huge load of sand, but from Denver to Plattesmouth has not the semblance of a cañon. The trouble with the Platte is that it carries too much sand. A river of given volume and velocity can carry in suspension only a definite load of sediment of giren coarseness. When that limit is exceeded the excess will be precipitated upon the bottom protecting it from the scour of the gritty particles which are carried in suspension. But if the supply of sand be not in excess of the power of the current to keep it in suspension, none will be deposited except locally, and the bed-rock will experience the full attrition of the sandblast. The Platte is the case of an overloaded stream while the Colorado is slightly underloaded and in a condition to produce the maximum erosion.

The study of the Plateau Country has during the last nine years been the work of the Survey under Prof. J. W. Powell. Comparatively little has been published about it because it has been felt by him that until the subject could be presented in systematic and thoroughly intelligible form it would be a mistake to accumulate fragmentary literature and encumber a splendid subject with a chaos of unconnected observations. But the work approaches completion and has developed into form in the minds of the workers, and it is hoped that the results will soon be before the world. If the geology of the Plateau Country shall therein be set forth in a manner commensurate with its importance, and full justice done to the revelations it affords, I believe that physical geology will have received important additions. I cannot close without paying a just tribute to Prof. Powell, the director of their work. His direction of the Survey has not been limited to the perfunctory duties of an administrative officer. On the contrary he has furnished those whom he has called to his assistance with methods of 
observation and principles which have worked like a master-key in opening to our understanding the meaning of this wonderful region. Without those methods and principles it would have been of comparatively little utility to attempt to solve the problems of such a region. Those whose privilege it has been to carry them into practice will ever be glad to acknowledge how great is their indebtedness.

\section{INCLINATION OF THE AXES OF CYCLONES AND ANTICYCLONES}

T HAVE during the last seven years endeavoured, though apparently without much effect, to direct the attention of meteorologists to a law which I conceive to be of very high importance in relation to the theory of the movements of the atmosphere. The law to which I refer is this:-The movements of the upper-currents prove that the axis of a progressive cyclonic circulation is commonly inclined, so that the extremity nearest to the earth's surface is considerably in advance of that in the higher regions of the atmosphere. A barometric minimum consequently occurs at any locality on the earth's surface some hours before the corresponding minimum in the higher regions passes over the same spot "Laws of the Winds Prevailing in Western Europe," pp. 156 to 162 , 1872; Meteorological Magazine, vol. x. pp. 92 to 93, 1875 ; Quarterly Journal of the Meteorological Society, October, 1877 , pp. 440 to 445 ). I have also pointed out that the axis of an anticyclonic circulation has, at least in some instances, a similar inclination; a point which will be discussed more fully in a future paper.

I hope that the results, strongly confirmatory of this law, which Prof. Loomis has recently derived from his examination of the wind and barometer reports from Mount Washington, Mount Mitchell, and Pike's Peak, will attract more attention than my own deductions from upper-current observations have done. In his tenth paper of "Contributions to Meteorology" (American Journal of Science and Arts, January, 1879), Prof. Loomis shows that with very few exceptions the barometric minima occur at the base of a mountain considerably earlier than at the summit, the retardation amounting to about one hour for an elevation of from 900 to $\mathrm{I}, 300 \mathrm{feet}$, and that the maxima appear to follow the same law.

Other points of agreement between the results of cloud observations in Europe, and those obtained from the reports of the mountain observatories in America, seem to me to be of great interest. I would especially call attention to the substantial coincidence of these results as regards, first, the rarity of easterly upper-currents, as compared with easterly surface-winds; and secondly, the higher, and also less variable, value of the angle made by the northerly, than that made by the westerly uppercurrents, with the direction of the centre of lowest pressure at the earth's surface.

W. CLEMENT LEY

\section{BARTOLOMEO GASTALDI}

SINCE the last anniversary of the Geological Society many distinguished men among its members, both in this and foreign countries, have been removed by death. We regret to have to add to the sad list the name of Prof. Gastaldi, the well-known head of the Italian Geological Survey.

Bartolomeo Gastaldi was born at Turin, in the year 1818 , and was originally destined by his father for a legal career; his fondness for geological studies, however, proved too strong to be repressed, and he was eventually entered as a student at the École des Mines at Paris. Here, and throughout his subsequent career, he enjoyed the friendship of Quintino Sella, who afterwards became so distinguished alike in Italian scientific and political circles.
Gastaldi had reached the age of twenty-eight before his first scientific memoir was published, and his earliest essays in this direction were devoted to anatomical and palæontological questions. Before long, however, he seems to have discovered that the true bent of his genius was towards physical geology. In his studies in this department of science he was greatly aided by his powers as a pedestrian, and he soon made himself familiar with all the southern spurs of the Alpine chain. In company with his friend Sella he founded the Italian Alpine Club, of which he was the second president.

He succeeded Sella as Professor of Geology at the Engineering School of Turin, and subsequently became Professor also at the University. During the later years of his life the work of the Geological Survey, of which he was made director by the Italian Government, occupied much of his attention, and to his energy and capacity much of the success which has already attended that important work is due.

No less than thirty papers on various branches of geological science have proceeded from Gastaldi's pen. He was an advocate, during his later years, of extreme: views upon glacial subjects, and many of the views which he propounded on this and on other questions of Alpine geology have not been generally accepted by the geologists of other countries. In some of his speculations, indeed, his boldness seems to have outrun his caution. Those who had the happiness of a personal acquaintanceship with Gastaldi describe him as a most sanguine and earnest student and a warm-hearted friend.

Prof. Gastaldi was a Corresponding Member of the Geological Society of London, and received similar honours from the academies of many other foreign countries. In Turin, where he spent the greater part of his life, and where he occupied the position of a Common Councillor, he was very greatly respected and beloved; this fact is testified to by the circumstance that at his funeral more than three thousand people followed his remains to the cemetery.

\section{ON THE DETERMINATION OF ABSOLUTE} PITCH BY THE COMMON HARMONIUM ${ }^{1}$

THE methods described depend upon the principle that the absolute frequencies of vibration of two musical notes can be deduced from the interval between them, i.e., the ratio of their frequencies, and the number of beats which they occasion in a given time when sounded together. For example, if $x$ and $y$ denote the frequencies of two notes whose interval is an equal temperament major third, we know that $y=1.25992 x$. At the same time the number of beats heard in a second, depending upon the deviation of the third from true intonation, is $4 y-5 x$. In the case of the harmonium these beats are readily counted with the aid of a resonator tuned to the common over-tone, and thus are obtained two equations from which the absolute values of $x$ and $y$ may be found by the simplest arithmetic.

Of course, in practice, the truth of an equal temperament third could not be taken for granted, but the difficulty thence arising would be easily met by including in the counting all the three major thirds which together make up an octave. Suppose, for example, that the frequencies of $c, e, g \frac{t}{t} c^{\prime}$ are respectively $x, y, z, 2 x$, and that the beats per second between $x$ and $y$ are $a$, between $y$ and $z$ are $b$, and between $z$ and $2 x$ are $c$. Then,

$$
\begin{aligned}
& 4 y-5 x=a, \\
& 4 z-5 y=b, \\
& 8 x-5 z=c,
\end{aligned}
$$

from which

$$
\begin{aligned}
& x=\frac{1}{3}(25 a+20 b+16 c), \\
& y=\frac{1}{3}(32 a+25 b+20 c), \\
& z=\frac{1}{3}(40 a+32 b+25 c) .
\end{aligned}
$$

1 A bitract of a yaper read refore the Miruical Ass zciation, December * if 7 , i.y i.ord Kayle ght F.K.S. 